Review Paper

\title{
LA RECEPCIÓN DE LA LITERATURA ESPAÑOLA EN LAS TRADUCCIONES Y LOS TEXTOS CRÍTICOS DE RADIVOJE KONSTANTINOVIĆ
}

\author{
UDC 821.134.2.09(497.11)
}

\begin{abstract}
Vladimir Karanović
Universidad de Belgrado, Facultad de Filología, Departamento de Estudios Ibéricos,
\end{abstract} Belgrado, Serbia

\begin{abstract}
Resumen. La primera traducción de una obra literaria es simultáneamente el primer acto crítico de la obra original en un ámbito cultural extranjero. Para realizar una traducción con éxito, el traductor debe mostrar no solo el interés por la materia traducida, maestría en la selección de las obras mediante cuya traducción refuerza el impacto en la cultura local, sino debe tener varias competencias crítico e históricoliterarias, imprescindibles en el proceso de la valorización crítica y la recepción general de la obra. Durante casi un medio siglo de la presencia del hispanismo académico profesional en Yugoslavia y Serbia, Radivoje Konstantinović, romanista, traductor y profesor de literatura francesa, participó activamente en los numerosos acontecimientos importantes para los estudios hispánicos y el hispanismo general en nuestro país. En su impresionante biografía académica encontramos firmes e importantes esfuerzos de ofrecer al público interesado, profesional y aficionado, traducciones de los clásicos selectos de las literaturas española e hispanoamericana, acompañadas por textos pertenecientes al campo crítico e histórico-literario. El propósito de este artículo es analizar las traducciones, los textos complementarios de las traducciones realizadas (introducciones o postfacios) y las ediciones editadas por Radivoje Konstantinović, pertenecientes exclusivamente a la literatura española, mostrar el contexto de su concepción y realización, la ruta de la recepción, especialmente en el ámbito académico profesional, y finalmente explicar el potencial impacto e importancia en la literatura traducida y en los estudios hispánicos serbios en general.
\end{abstract}

Palabras clave: literatura española, teoría de la recepción, traducción literaria, estudios hispánicos en Serbia, Radivoje Konstantinović

Submitted July 2, 2019; Accepted September 23, 2019

Corresponding author: Vladimir Karanović

University of Belgrade, Faculty of Philology

E-mail: vladimir.karanovic@ fil.bg.ac.rs 


\section{INTRODUCCIÓN}

En la teoría de la literatura de las últimas décadas fácilmente podemos detectar una tendencia al individualismo relativista posmoderno, relacionado con la estética de la recepción (García Berrio y Hernández Fernández 2008, 128). De ahí la vigente imagen universal del lector como una construcción que cierra en sí el circuito del significado de una obra literaria. Hans Robert Jauss (1921-1997), como fundador de la estética de la recepción, en sus estudios críticos y revisiones teóricas posteriores, efectuadas durante los años setenta del siglo XX, intenta examinar los procesos de recepción y acción, integrados en la noción de efecto estético y experiencia estética, que formaban parte de su sistema teórico original y tenían gran influencia en el proceso receptivo de una obra literaria. Según Fernando Gómez Redondo (2008, 316), "el significado posible de un texto se realiza mediante la interacción de la capacidad receptiva del lector y de las previsiones que pueda plantear el autor en el ejercicio de su creación". En este sentido, Wolfgang Iser (19262007), otro representante de la teoría de la recepción, diferencia a un lector implícito, poseedor de la perspectiva que existe en su interior, portador de una imagen concreta de lector y protagonista de un proceso de transformación, mediante el cual se transfieren las estructuras del texto, a través de los actos de representación, al capital de experiencia del lector. La otra modalidad radica en la figura del lector real, "el individuo que pone en funcionamiento una determinada serie de experiencias para reconstruir las imágenes de que el texto es portador.” (apud Gómez Redondo 2008, 317).

La primera traducción de una obra literaria es simultáneamente el primer acto crítico de la obra original en un ámbito cultural extranjero. Para realizar una traducción con éxito, el traductor debe mostrar no solo el interés por la materia traducida, maestría en la selección de las obras mediante cuya traducción refuerza el impacto en la cultura local, sino el texto debe ejercer una considerable influencia en el traductor (Mančić 2010, 40). Explicar el papel y el impacto de la literatura traducida en una literatura nacional autóctona significa responder a las siguientes preguntas: 1) ¿qué es lo que se traduce?, 2) ¿por qué se traduce?, 3) ¿cómo se traduce?, y finalmente 4) ¿qué influencia ejercen las traducciones realizadas? (Janićijević 1977, 40). La traducción es, en el fondo, un hecho que testimonia la recepción de una obra extranjera en una literatura nacional. De ahí que el traductor representa el primer eslabón en este proceso o el primer lector interesado, el primer intérprete y evaluador de un escritor extranjero, previamente ajeno al público nacional (Bunjak 1998, 20). La mera elección de la obra traducida, el proceso de traducción y finalmente su publicación, llevan un fuerte sello de la recepción (en cierto sentido del concepto).

Entre los romanistas e hispanistas que han dejado huella significativa en la historia de los estudios hispánicos en Serbia, Radivoje Konstantinović destaca, entre otras características, por su espíritu inventivo, su curiosidad inmanente y por una lógica e indicativa elección de temas tratados, obras traducidas y análisis realizados durante las décadas del desarrollo de nuestro hispanismo. Además, su formación erudita y humanística lo ha hecho un representante ideal y adecuado para el análisis de la imagen del lector ideal, informado o modelo, una de las concepciones fundamentales en la recepción de una literatura extranjera, o concretamente, de las letras españolas en nuestro ámbito académico y cultural.

El propósito de este artículo es analizar la actividad hispanista de Radivoje Konstantinović: las traducciones, los textos complementarios de las traducciones realizadas (introducciones o postfacios) y las ediciones editadas por él, pertenecientes exclusivamente a la literatura española. Además, se pretende mostrar el contexto de su desarrollo y 
realización, la ruta de la recepción, especialmente en el ámbito académico profesional, y finalmente explicar su potencial impacto e importancia en la literatura traducida y en los estudios hispánicos serbios en general. Nuestro análisis lo vamos a organizar según los criterios cronológicos y temáticos de la materia traducida, en conformidad con el sistema establecido dentro de la historia de la literatura española.

\section{LAS LETRAS ESPAÑOLAS EN EL CONTEXTO ACADÉMICO YUGOSLAVO / SERBIO}

El hispanismo académico serbio nació en la Universidad de Belgrado en 1951 en la Facultad de Filosofía y Letras, dentro de los estudios románicos. La lengua española fue una asignatura optativa, enseñada por José Bort Vela. Una década después, en 1962, el español obtuvo el estatus de la lengua auxiliar y los primeros profesores son Ljiljana Pavlović Samurović y el argentino Juan Octavio Prenz, profesor, poeta e ilustre hispanista. El Grupo de lengua española y literaturas hispánicas fue fundado en 1971 en la Facultad de Filología por Ljiljana Pavlović Samurović como parte del Departamento de estudios románicos. Los primeros hispanistas se formaron en 1975 y durante las décadas posteriores hasta la actualidad, el Departamento de Estudios Ibéricos ha sido y sigue siendo uno de los más prestigiosos en el mundo académico de esta parte de Europa. No obstante, durante los primeros pasos institucionales, el Departamento tuvo el apoyo de los profesores romanistas e italianistas, siendo campos científicos más cercanos a la filología hispánica (Stojanović y Soldatić 2015).

Los años setenta del siglo XX van a cambiar completamente la perspectiva de la recepción de las obras literarias españolas e hispanoamericanas, porque por primera vez contamos con el desarrollo sostenible del hispanismo institucional, encarnado en el nacimiento de los estudios hispánicos en la Universidad de Belgrado. De ahí que el profesor Dalibor Soldatić $(2010,22)$ se refiere a este hecho destacando que "[e]l estudio sistemático de la lengua y literatura española comienza en realidad en 1971 cuando empieza a estudiarse el idioma español en la Facultad de Filología de la Universidad de Belgrado. Antes de ello, los contactos eran esporádicos, y consistían, en la mayoría de los casos en traducciones que poco a poco afirmaban las literaturas hispánicas en el ámbito serbio y preparaban el terreno para un enfoque más ambicioso y sistemático."

Desde entonces el horizonte de expectativas del público serbio y yugoslavo sufrió unos cambios drásticos, y los estándares de traducción y la actividad crítica cambiaron considerablemente.

En este contexto es necesario destacar el gran protagonismo del profesor Konstantinović, constantemente consciente de su imprescindible tarea de protector y promotor de los estudios hispánicos y comparados, dentro de los estudios románicos. Además de su actividad académica, se dedicó a la traducción y promoción de varias obras españolas y las primeras traducciones al serbio, pilares de la recepción de la literatura española en nuestro ambiente cultural. También, no podemos dejar de mencionar el gran apoyo que ofreció a los jóvenes hispanistas y profesores universitarios en Serbia y la región. Siendo así, el profesor Konstantinović merece el calificativo de uno de los primeros romanistas serbios interesado en los temas hispánicos que se ha dedicado sistemáticamente a la actividad académica y científica en este campo. 


\section{LA NOVELA PICARESCA ESPAÑOLA}

La recepción de la novela picaresca española en el ambiente literario yugoslavo y serbio data de mediados del siglo XX, para ser exactos de 1951, cuando por primera vez al serbo-croata se tradujeron las dos novelas más célebres de este corpus literario, Lazarillo de Tormes ${ }^{1}$ e Historia de la vida del buscón ${ }^{2}$ (Karanović 2017, 219).

Después de la traducción de la primera novela picaresca al serbio, realizada en 1995 por Jasna Stojanovic ${ }^{3}$, entre los hispanistas serbios despierta el interés por este subgénero original introducido al ambiente cultural nacional y regional. En este sentido es muy significativa la contribución de Radivoje Konstantinović, quien en 2003 publica la primera traducción al serbio de la novela picaresca Historia de la vida del buscón (Životopis pustolova po imenu don Pablos $)^{4}$ de Francisco de Quevedo. Al tratarse de una obra de la primera mitad del siglo XVII (1626) con elementos típicos y originales del llamado "español áureo", la traducción trae consigo un abanico de retos profesionales para un traductor responsable y consciente de su oficio. Sin lugar a dudas, esta traducción destaca por su minuciosidad profesional, el tono adecuado y el espíritu picaresco fielmente reproducido y presentado al lector serbio. Además, el traductor supo analizar los elementos estilísticos y linguiísticos inmanentes al conceptismo quevedesco (metáforas extravagantes, juegos de palabras, asociaciones de ideas, contrastes, comparaciones e hipérbolas, humorismo, alusiones, figuras grotescas, ironía, etc.), manejándolos con éxito e ilustrándolos mediante los equivalentes serbios y fórmulas ya ampliamente conocidas en la tradición picaresca universal.

Esta obra obtuvo el premio de la Fundación "Radoje Tatić" en 2004, reservado para las traducciones del español y portugués al serbio. En su argumentación del premio concedido ${ }^{5}$, el jurado (Gordana Ćirjanić, Branislav Prelević, Dalibor Soldatić, Živojin Kara-Pešić e Ivan Milenković) destacó los criterios de su decisión: el considerable grado de calidad de la traducción, su pureza, certeza, relación de la belleza y adecuación de la expresión en serbio, verosimilitud del contenido y de los equivalentes serbios, la importancia de la obra traducida en la cultura española y serbia, y por fin, el peso del proyecto traductor. El jurado era consciente de la importancia de la traducción de una obra picaresca, un clásico del Siglo de oro, y una de las obras más significativas de la literatura española. En este contexto se acentuó la competencia del traductor y alto nivel de conocimiento de las circunstancias históricas y sociales de la España barroca, la vida de Quevedo, su poética novelesca, el impacto del género picaresco en la literatura nacional, etc. Con especial atención se valoraron los fragmentos de la traducción que ilustraban las figuras estilísticas y retóricas quevedescas, el argot picaresco, característico del hampa y los estratos sociales más bajos. Y no solo eso, Radivoje Konstantinović supo sortear las trampas del texto áureo español, acertar con el humor

\footnotetext{
${ }^{1}$ 1951. Lazarillo de Tormes. Sa španjolskog preveo Jakša Sedmak, za tisak priredio Josip Tabak. Zagreb: Mladost. La misma traducción se reimprimió después con el subtítulo original traducido: 1964. Lazarillo de Tormes, Pikarski roman nepoznatog španjolskog autora iz XVI stoljeća. Preveo Jakša Sedmak, za štampu priredio Josip Tabak. Zagreb: Naprijed.

${ }^{2}$ Francisco de Quevedo. 1951. Životopis lupeža. Sa španjolskoga preveo i napomenama propratio Josip Tabak. Zagreb: Novo pokoljenje. La misma traducción se reimprimió en la edición corregida y reelaborada: Fransisko de Kevedo. 1961. Životopis lupeža. Preveo sa španskog Josip Tabak. Beograd: Izdavačko preduzeće Rad.

3 1995. Život Lazarčića sa Tormesa, njegove zgode $i$ nezgode. Prevela sa starošpanskog jezika, pogovor, bibliografiju i beleške sačinila Jasna Stojanović. Beograd: Lapis.

${ }^{4}$ Fransisko de Kevedo. 2003. Životopis pustolova po imenu don Pablos. Prevod sa španskog, predgovor i napomene Radivoje Konstantinović. Beograd: Srpska književna zadruga.

${ }^{5}$ Fond „Radoje Tatič“. 2004. „Obrazloženje žirija“. 29/03/2019.

http://www.forata.org/sr/fond/nagrada/116/Obrazlo\%C5\%BEenje-\%C5\%BEirija-2004.htm.
} 
específico y original quevedesco, basado en varios grados: desde una ironía ligera hasta el cinismo agresivo, de vez en cuando cargado de insultos o agresión verbal. Al mismo tiempo, se hace constancia de la simplicidad y conceptismo quevedesco, muy bien traducido al serbio sin perder su sentido original. Los elogios del jurado se dirigieron hacia el protagonista, Pablos de Segovia, cuya bipolaridad, de un marginado y personaje trágico vs. víctima del sistema y de las circunstancias históricas, sirvió al traductor para presentar el arte narrativo de Francisco de Quevedo y ofrecer a los lectores serbios una obra extraordinaria de la literatura española.

La importancia de la novela de Quevedo en la historia de la picaresca española es enorme, tanto por su originalidad como por los juegos del autor con el género y la reivindicación de las fronteras poéticas del subgénero. Parece que este conocimiento y el rigor profesional han sido los elementos cruciales para la inspiración a seguir con la dedicación a la picaresca española mediante las traducciones entre los hispanistas y los traductores serbios del momento, así que muy pronto, en 2004, la hispanista y traductora Aleksandra Mančić publicó su versión de la traducción de la misma novela, esta vez con el título original completo: Historia de la vida del buscón, llamado don Pablos, ejemplo de vagamundos y espejo de tacaños ${ }^{6}$. La aparición de una traducción más de la misma obra abrió un gran abanico de posibilidades para los hispanistas y el público interesado, encaminado a valorar y analizar esta valiosa obra de la prosa del barroco español desde varias perspectivas, especialmente para poder comparar dos visiones e interpretaciones textuales realizadas por traductores e hispanistas prestigiosos, cuya obra ha sido reconocida durante su vida profesional con relevantes premios a la traducción y ensayística en Serbia. Desde entonces también surgió la base fundamental para los estudios y análisis comparativos, iniciados en los textos ensayísticos y artículos científicos (Karanović 2017, 220-221).

Consideramos que es de gran importancia también el análisis de los textos críticos, que acompañan las traducciones de las novelas picarescas al serbio. Se trata de textos escritos por los hispanistas o especialistas en temas de las literaturas románicas, o sea, lectores modelo, intérpretes y críticos efectivamente ideales, especialmente por sus competencias, nivel informativo y el alto grado de expectativas en cuanto a la obra original. Estos textos nos pueden servir para obtener informaciones sobre el contexto del traductor, sus motivos para empezar el trabajo realizado, sobre el público meta y sobre el ambiente cultural que deja la obra traducida en su territorio literario (Karanović 2017, 222).

Teniendo esto en cuenta, hemos comprobado que el momento crucial en la recepción y la traducción de la novela picaresca de Francisco de Quevedo en la esfera del hispanismo académico y profesional en Serbia fue la publicación de su primera traducción serbia en 2003. En su edición, Radivoje Konstantinović rompió con la tradición predominante en las traducciones del español anteriores de acompañarlas por unos textos breves, superficiales y generales (el caso de las primeras traducciones del español al serbo-croata a mediados del siglo XX), creando un minucioso e interesante estudio de la obra quevedesca y de varios aspectos esenciales de la novela picaresca traducida. Su texto titulado "Introducción" („Predgovor“) guarda numerosos datos biográficos sobre el autor barroco español, pero también contiene varias valoraciones de su obra, un aspecto original y útil para el proceso de la recepción de la obra picaresca en nuestro contexto cultural. Como afirma Konstantinović (2003, X), la obra picaresca de Quevedo no es suficientemente conocida

${ }^{6}$ Fransisko de Kevedo. 2004. Žitije vrdalame po imenu don Pablos, primernog probisveta, slike i prilike mufljuza. Prevela Aleksandra Mančić. Beograd: Izdavačko preduzeće Rad. 
fuera de las fronteras nacionales españolas por la estructura complicada de su lenguaje y su frase compleja y difícil de traducir. Su estilo específico, su léxico original, sus figuras retóricas lo hacen uno de los escritores españoles más originales de la historia de la literatura nacional española. La originalidad de su poesía está ilustrada en este breve texto a través de la traducción de uno de los sonetos amorosos y reflexivos más conocidos de la literatura española: Amor constante más allá de la muerte, realizada por Radivoje Konstantinović y Branimir Živojinović (2003, XIII). Además, en algunos fragmentos del texto Konstantinović destaca el papel político que tenía Quevedo durante un periodo de su vida. Así el lector serbio interesado tiene la posibilidad de saber algo más de lo ya expuesto en los textos anteriores y de profundizar considerablemente sus conocimientos de la materia. En cuanto a la famosísima novela de Quevedo, se acentúa popularidad en la historia de la literatura española y se analizan brevemente los personajes y la ideología quevedesca, cuyo impacto en la estructura novelesca resulta bastante obvio. Según Konstantinović (2003, XVI-XVII), Quevedo es un maestro del humor y la grotesca, fiel a su conceptismo original, en el que nos ofrece un cuidado estilo, basado en el pensamiento asociativo y en varios niveles linguíísticos: desde el lenguaje ceremonial y culto hasta el lenguaje cotidiano, popular e inmanente al hampa picaresca. También, resulta original e interesante el paralelo subrayado por Konstantinović entre la época de Quevedo y la nuestra, símbolo de crisis personal y colectiva (Karanović 2017, 223-224).

\section{LA NARRATIVA BREVE DE LOS AUTORES ESPAÑOLES}

A diferencia del gran interés por la narrativa breve hispanoamericana, especialmente la contemporánea, los cuentos y las novelas cortas españoles hasta ahora han sido solo esporádicamente presentes en las traducciones al serbo-croata y serbio. ${ }^{7}$

Entre las pocas antologías de la narrativa breve española destaca la Antología del cuento español desde Cervantes hasta la actualidad (Antologija španske pripovetke od Servantesa do danas), publicada en 1984 y editada precisamente por Radivoje Konstantinović.

En el texto introductorio titulado "Los cuentistas españoles” (,Španski pripovedači“, 713), el autor se refiere a la popularidad de los escritores hispanoamericanos contemporáneos y su boom literario en el contexto global, destacando al mismo tiempo el posible error recepcional en cuanto a la literatura y la narrativa española, concebida en la Península Ibérica. El editor de la antología en este texto demuestra su gran competencia como historiador de literatura, capaz de dar un minucioso panorama del desarrollo de la narrativa corta española desde la Edad Media hasta la segunda mitad del siglo XX. A pesar de su breve extensión, este texto reconoce el gran impacto que tenía la novela corta española desde la época cervantina, siendo el escritor clásico español y universal el modelo para las generaciones de los futuros cuentistas. Konstantinović se empeña en destacar y explicar las características de la narrativa cervantina, sus elementos originales e inmanentes, prestando especial atención a la diferencia con otros cuentistas y novelistas europeos de la época en cuestión. Konstantinović hizo una ilustrativa, adecuada e interesante selección de autores españoles del siglo XIX, cuando el Romanticismo, el Costumbrismo y el Realismo habían engendrado para la literatura nacional y europea muchos nombres valiosos e influyentes

\footnotetext{
${ }^{7}$ La primera antología de cuentos españoles publicada en serbo-croata fue: 1949. Španjolske pripovijetke. Preveo sa španjolskoga Josip Tabak, Zagreb: Novo pokoljenje, Biblioteka izabranih pripovijetki, Kolo V, Svezak 4.
} 
que formaban parte de la tradición literaria española. Y por fin, puesto que la antología aparece en Yugoslavia en el periodo de la llamada "transición o la democratización española", después de la época franquista durante la cual los dos países no tuvieron relaciones diplomáticas ni muchos contactos políticos o sociales, Konstantinović $(1984,13)$ quiere explicar el contexto y la idea según los cuales se traduce, edita y publica este libro:

Posle izolacije duge četiri decenije, prouzrokovane građanskim ratom i Frankovom diktaturom, Španija se polako vraća Evropi i svetu pokazujući da njena savremena književnost dostojno nastavlja svoju veliku tradiciju. (...) Od srednjeg veka do danas pripovetka je omiljen književni oblik u Španiji. Iako ni u Španiji, kao ni drugde u Evropi, pripovetka nema prestiž romana ili drame, ona u mnogo čemu bolje odražava ne samo razvoj čitave španske književnosti nego i duhovnu istoriju španskog naroda, njegova htenja i verovanja, nade i zablude. Naklonost španskih pisaca prema pripoveci, uprkos strogim književnim zakonodavcima, jeste jedan oblik vernosti kastiljanskom jeziku, i možda ispunjenje jednog trajnog zaveta ili duga besmrtnom tvorcu Uzornih priča. ${ }^{8}$

La antología consta de veinte cuentos o novelas cortas, empieza con la famosísima novela corta y ejemplar de Cervantes - Rinconete y Cortadillo, cediendo el resto de las páginas a los cuentos de los siglos XIX y XX. La mitad de los títulos fue traducida por Duško Vrtunski, uno de los ilustres especialistas en temas hispánicos, en el momento de la publicación de la antología ya afirmado traductor de las Novelas ejemplares de Cervantes, cuya traducción integral se publicó en serbio en 1981. Los cuentos traducidos por Konstantinović son: El afrancesado de Pedro Antonio de Alarcón, El Monte de las Ánimas de Gustavo Adolfo Bécquer, El fondo del alma de Emilia Pardo Bazán, ¡Adiós, Cordera! de Leopoldo Alas Clarín, Dimoni de Vicente Blasco Ibáñez, El hechizado de Francisco Ayala, Aniversario de Luis Romero, El vendedor de corbatas de José Amillo, El rescate de Medrado Fraile y Los chicos de Ana María Matute.

Siendo esta antología una selección bien hecha y minuciosamente elaborada, acompañada por el aparato crítico elemental y los textos complementarios, es obvio que la intención principal fue informar al lector interesado sobre las principales tendencias en la narrativa breve española, con especial atención prestada a los cuentos de los siglos XIX y el XX. Teniendo en cuenta el contexto de la aparición de la antología, las circunstancias históricas y sociales de España y recién establecidos lazos entre la España de la transición democrática y Yugoslavia, la importancia de este proyecto editorial aumenta considerablemente. Como editor, traductor y autor del aparato crítico de la edición, Konstantinović sigue mostrando la considerable competencia en temas españoles y un excelente talento de traductor capaz de hacer una traducción auténtica, relevante, en conformidad con el espíritu y el contexto literario de la narrativa breve española. También, detectamos una clara intención educativa e ilustrativa de informar al lector local, educar al lector aficionado o profesional, y finalmente, acercar las

\footnotetext{
${ }^{8}$ Tras las cuatro décadas de aislamiento, causado por la Guerra civil y la dictadura de Franco, España regresa lentamente a Europa y al mundo, mostrando que su literatura contemporánea continúa su gran tradición. (...) Desde la Edad Media hasta la actualidad, el cuento fue el género literario predilecto en España. Aunque en España, igual que en otras partes de Europa, el cuento no tiene el prestigio de una novela o un drama, en muchos aspectos refleja mejor no solo el desarrollo de toda la literatura española, sino también la historia espiritual de los españoles, sus deseos y creencias, esperanzas y engaños. La inclinación de los escritores españoles al cuento, a pesar de la rigidez de los legisladores literarios, representa una forma de lealtad a la lengua castellana, y quizás, el cumplimiento de un legado permanente, o de una deuda, al creador inmortal de las Novelas ejemplares. (Traducido por V.K.)
} 
dos culturas tan distintas posibilitando estudios comparativos o simplemente la recepción de la literatura española entre diferentes categorías de lectores serbios.

Varios años después (1991), en su Antología de novelas cortas y cuentos clásicos (Antologija klasičnih novela i kratkih priča), Jovan Janićijević incluyó dos cuentos traducidos por Konstantinović, ya publicados en la antología analizada: Dimoni de Vicente Blasco Ibáñez y El fondo del alma de Emilia Pardo Bazán. El texto introductorio titulado "La novela corta en busca de un secreto” („Novela u potrazi za tajnom“, 5-8) sirve para justificar la selección de los cuentos italianos, españoles, checos, polacos y escandinavos, entre los cuales se encuentran los famosos cuentos de los dos realistas / naturalistas españoles.

\section{LA POESIA ESPAÑOLA DEL SIGLO XX}

Radivoje Konstantinović, además de su interés práctico por la traducción literaria, ha mostrado considerable competencia en asuntos teóricos relacionados con la traducción. En uno de los ensayos publicados en la colección de sus textos recopilados (Konstantinović 2010, 29-30) analiza los casos y ejemplos de la traducción y transformación de una imagen a otra durante el proceso de la traducción poética, destacando el papel de las competencias histórico-literarias o culturales del traductor como elementos imprescindibles para realizar una traducción valiosa y digna de las generaciones venideras. Los límites de la libertad del traductor de poesía suelen coincidir con el marco literario en el que habita el poeta, así que de ahí la reivindicación y la reflexión como los procesos cruciales en la actividad de un traductor relevante.

Durante su fructífera actividad vinculada al hispanismo, el profesor Konstantinović se ha dedicado a varios temas y autores de poesía en la lengua española, mostrando un interés especial por la poesía hispanoamericana, concretamente por la obra de Jorge Luis Borges. Sin embargo, en cuanto a la poesía exclusivamente española, en su foco se encuentran dos autores de distintos periodos del siglo XX: Federico García Lorca y Justo Jorge Padrón. A diferencia de su actividad como traductor de la obra de Borges, nuestro eminente romanista analiza a los poetas españoles solo en un nivel crítico-literario e histórico-literario, pretendiendo ofrecer al lector serbio ediciones minuciosamente preparadas aunque sin grandes pretensiones académicas, al tratarse de ediciones populares.

En primer lugar, destacamos la dedicación a la obra poética de Federico García Lorca, cuya presencia en el ámbito cultural yugoslavo y serbio ya cuenta con una larga tradición, concretamente, desde los años treinta del siglo XX. En 2006 la editorial belgradense "Draganić" publicó una selección de la poesía lorquiana editada por Radivoje Konstantinović. Se trata de una recopilación de poemas traducidos por Miodrag Gardić, uno de los traductores especializados en los textos lorquianos. Pero nos ha llamado la atención el posfacio titulado "Federico García Lorca” („Federiko Garsija Lorka“, 151-154), en el que Konstantinović presenta en breves líneas la obra del famoso poeta español. Al acentuar la importancia de la obra de García Lorca en la literatura universal, comparándola y poniéndola a la altura de la de Cervantes, el eminente romanista explica las causas de su popularidad y el impacto dentro de otras culturas del mundo. Se trata de la sinceridad y la belleza estética de los poemas, aunque es importante que no se olviden los elementos biográficos, especialmente la trágica muerte del poeta español. A continuación el autor presenta varios datos biográficos de García Lorca y el contexto histórico-literario de su poesía y su obra en general. Aquí sorprende la maestría de Konstantinović en dosificar los hechos y las informaciones 
relevantes de la vida lorquiana y de hacer una selección adecuada para un público local más amplio. En el último segmento del texto se valora positivamente la gran importancia de la actividad traductora del periodista serbio Miodrag Gardić, como uno de los pioneros para la recepción de la obra de Federico García Lorca en nuestro ambiente cultural y la literatura traducida serbia.

En cuanto a la poesía contemporánea española, el nombre de Radivoje Konstantinović aparece en el contexto de crítico y reseñador de las antologías publicadas. Así encontramos una breve valoración de la obra poética del poeta español Justo Jorge Padrón ${ }^{9}$, cuya antología fue publicada en serbio gracias a la excelente actividad traductora de Branislav Prelević. En la tapa interior del libro figura un breve texto de Konstantinović en el que destaca la importancia del poeta en el contexto de la poesía española del momento, como una síntesis de la tradición y nuevos impulsos poéticos. Al final nos informa sobre la densidad de su poesía y los cuatro elementos del mundo de la Antigüedad, colindándose y entrelazándose, formando un universo poético sensible, tierno pero a la vez lleno de una alegría trágica.

\section{CONCLUSIONES}

La traducción de los clásicos literarios españoles en nuestra cultura ha tenido impactos positivos desde diferentes puntos de vista. La recepción de la literatura española en la actividad hispanista de Radivoje Konstantinović encuadra perfectamente en las nuevas tendencias en cuanto al corpus de los textos pertenecientes al hispanismo serbio: se traducen y teóricamente explican las obras cuyo análisis se realiza por su concepción estética, por su propia calidad, sin pretensiones ideológicas; sus traductores y críticos son eminentes expertos en la materia de los estudios hispánicos o románicos y autores de los textos complementarios - relevantes estudiosos que intentan revalorizar o simplemente fomentar el estudio de varios aspectos de las obras españolas.

La elección de las obras traducidas y comentadas, efectuada por Radivoje Konstantinović, se basaba en los criterios estéticos, culturales, histórico-literarios, aunque no podemos negar una fuerte intención educativa dentro del contexto académico local y nacional (serbio) y su vocación de profesor universitario. La calidad filológica de las traducciones, el alto nivel de las ediciones, acompañadas por unos textos informativos, críticos e imprescindibles en un ambiente cultural nuevo, que todavía desconoce la literatura original (española) en su totalidad, testimonian sobre una visión profunda de la tarea emprendida y nos dejan espacio solo para valorizaciones archipositivas.

En cuanto a los temas elegidos e interpretaciones de las obras literarias españolas, en la historia de la recepción de la literatura española en nuestro contexto cultural Radivoje Konstantinović destaca por ser un auténtico ejemplo de un lector informado, ideal, modelo, que, según la teoría de Stanley Fish (apud Gómez Redondo 2008, 323), es "capaz de generar respuestas interpretativas que determinen una especie de contexto (...) [y] su último resultado sería el de vislumbrar una comunidad de comprensión; esa conjunción de valores y de efectos producidos por el texto coincidirían con el significado que la obra ha podido adquirir en un determinado momento de su vida temporal". En cada actividad, en cada texto

\footnotetext{
${ }^{9}$ Poeta, ensayista y traductor español y una figura importante de la generación poética de los años setenta del siglo XX. Sus libros han sido traducidos a más de treinta idiomas, incluidos inglés, ruso, sueco, serbo-croata, macedonio, albanés y búlgaro.
} 
crítico o en cada traducción realizada fácilmente se detecta una clara visión ilustrada, educativa y sistemática, de un erudita de corte humanístico, autor y traductor competente.

La actividad académica, científica y traductora de Radivoje Konstantinović ha sido y sigue siendo el modelo para los romanistas e hispanistas en Serbia y representa una base sólida no solo para los futuros estudios de los temas hispánicos y comparativos, sino también para el desarrollo de la traducción de las letras españolas en Serbia.

\section{BIBLIOGRAFÍA}

Bunjak, Petar. „O pitanju istorije recepcije strane književnosti““ Književna istorija, časopis za nauku o književnosti XXX (104): 5-26, 1998.

García Berrio, Antonio y Teresa Hernández Fernández. Crítica literaria (Iniciación al estudio de la literatura). Madrid: Cátedra, Crítica y estudios literarios, 2008

Gómez Redondo, Fernando. Manual de Crítica Literaria contemporánea. Madrid: Editorial Castalia, Castalia Universidad, 2008

Janićijević, Jovan. „Prevodna književnost.“ Kultura 38, 1977, pp. 40-50.

Janićijević, Jovan. „Novela u potrazi za tajnom“, Dno duše - Antologija klasičnih novela i kratkih priča. Izbor, predgovor i beleške Jovan Janićijević, 5-8. Beograd, Idea, Biblioteka „Dekameron“, Knjiga 2, 1991.

Karanović, Vladimir. "La recepción de la novela picaresca española en las traducciones y los textos críticoliterarios en Serbia.” Anali Filološkog fakulteta 29 (1), 2017, pp. 217-230.

Konstantinović, Radivoje. „O nekim problemima prevođenja poezije.“ Radivoje Konstantinović, O prevođenju poezije i drugi ogledi, Novi Sad, Adresa, 2010, pp. 29-33.

Mančić, Aleksandra. Prevod i kritika. Beograd, Institut za književnost i umetnost, 2010.

Soldatić, Dalibor. "Las literaturas hispánicas en Serbia." Colindancias 1, 2010, pp. 21-28, fecha de consulta 15/03/2019 en https://colindancias.uvt.ro/index.php/colindancias/article/view/99.

\section{Páginas web:}

Fond „Radoje Tatić“. „Obrazloženje žirija“, 2004, fecha de consulta 29/03/2019, en http://www.forata.org/sr/fond/nagrada/116/Obrazlo\%C5\%BEenje-\%C5\%Beirija 2004.htm.

Stojanović, Jasna y Dalibor Soldatić. „Istorijat Katedre za iberijske studije“, 2015, fecha de consulta 29/03/2019, en http://www.fil.bg.ac.rs/lang/sr/katedre/iberijske-studije/istorijat/.

\section{Traducciones y ediciones editadas / reseñadas:}

Blasko Ibanjes, Visente. „Dimoni.“ Dno duše - Antologija klasičnih novela i kratkih priča. Izbor, predgovor i beleške Jovan Janićijević, prevod Radivoje Konstantinović. Beograd, Idea, Biblioteka „Dekameron“, Knjiga 2, 1991, pp. 46-53.

Garsija Lorka, Federiko. Moć gitare. Preveo sa španskog Miodrag Gardić, priredio Radivoje Konstantinović, Beograd, Draganić, Biblioteka „Plavi krug“, 2006.

Kevedo, Fransisko de. Životopis pustolova po imenu don Pablos. Prevod sa španskog, predgovor i napomene Radivoje Konstantinović. Beograd, Srpska književna zadruga, 2003.

Konstantinović, Radivoje (priređivač). Antologija španske pripovetke od Servantesa do danas. Preveli Radivoje Konstantinović i Duško Vrtunski, Novi Sad, Bratstvo-Jedinstvo, 1984

Padron, Husto Horhe. Podići prazan list (Izabrane pesme). Izbor, prevod i pogovor Branislav Prelević, Vršac, KOV, Biblioteka „Evropska nagrada za književnost“, Knjiga 1, 1987.

Pardo Basan, Emilija. „Dno duše.“ Dno duše - Antologija klasičnih novela i kratkih priča. Izbor, predgovor i beleške Jovan Janićijević, prevod Radivoje Konstantinović. Beograd, Idea, Biblioteka „Dekameron“, Knjiga 2, 1991, pp. 99-102. 


\section{Introducciones y postfacios en las traducciones:}

Konstantinović, Radivoje. „Predgovor: Španski pripovedači“ In Antologija španske pripovetke od Servantesa do danas, izabrao i priredio Radivoje Konstantinović, preveli Radivoje Konstantinović i Duško Vrtunski. Novi Sad, Bratstvo-Jedinstvo, 1984, pp. 7-13.

Konstantinović, Radivoje. „Predgovor“ In Fransisko de Kevedo. Životopis pustolova po imenu don Pablos. Prevod sa španskog, predgovor i napomene Radivoje Konstantinović, VII-XVII. Beograd, Srpska književna zadruga, 2003.

Konstantinović, Radivoje. „Federiko Garsija Lorka.“ Federiko Garsija Lorka. Moć gitare. Preveo sa španskog Miodrag Gardić, priredio Radivoje Konstantinović. Beograd, Draganić, Biblioteka „Plavi krug“, 2006, pp. 151-154.

\section{RECEPCIJA ŠPANSKE KNJIŽEVNOSTI U PREVODIMA I KRITIČKIM TEKSTOVIMA RADIVOJA KONSTANTINOVIĆA}

Prevod nekog književnog dela ujedno predstavlja i prvi korak u njegovoj recepciji i kritici $u$ lokalnoj kulturnoj sredini. Kako bi se književni prevod uspešno realizovao, potrebno je da prevodilac pokaže ne samo jasno interesovanje za sadržaj koji prevodi, zavidno umeće u odabiru dela koja činom prevođenja približava određenoj kulturi, već $i$ brojne književnokritičke $i$ književnoistorijske kompetencije, neophodne u procesu kritičkog razmatranja i sveobuhvatne recepcije dela. Tokom bezmalo pola veka prisustva akademskog, naučnog i sistematičnog izučavanja hispanistike na našim prostorima, Radivoje Konstantinović, romanista, prevodilac $i$ profesor francuske književnosti, aktivno je učestvovao u važnim događajima za jugoslovensku $i$ srpsku hispanistiku, nastojeći da stručnoj javnosti, ali i najširem krugu zainteresovanih čitalaca, kroz prevode španskih i hispanoameričkih klasika približi hispanske književnosti. Zahvaljujući svojoj naučnoj, akademskoj i prevodilačkoj aktivnosti spada u red onih autora koji su neretko vođeni posrednim, francuskim uticajima na srpsku kulturu i hispanske studije, uspevali da u značajnoj meri doprinesu afirmaciji književnosti Iberijskog poluostrva koja je, usled niza okolnosti, kasno i samo delimično postala poznata našoj kulturnoj sredini. Cilj ovog članka je da predstavi prevode, propratne tekstove (predgovore i pogovore) i priređena izdanja Radivoja Konstantinovića iz oblasti španske književnosti, da ukaže na kontekst njihovog nastanka i putanju recepcije, pre svega u hispanističkoj akademskoj sredini, ali $i$ da objasni njihov značaj $i$ uticaj u srpskoj prevodnoj književnosti i u srpskoj hispanistici u najširem smislu.

Ključne reči: španska književnost, teorija recepcije, književno prevođenje, hispanistika u Srbiji, Radivoje Konstantinović 